\title{
Organization of a microsurgery laboratory ${ }^{1}$
}

\author{
Organização de laboratório de microcirurgia
}

\author{
Paulo Ney Aguiar Martins², Edna Frasson de Souza Montero ${ }^{3}$ \\ 1. Work performed at Transplant Surgery Department, Charité-Virchowklinikum, Humboldt Universität zu Berlin, Germany. \\ 2. MD, PhD, Department of Surgery, Division of Transplant Surgery, Brigham and Women’s Hospital, Harvard Medical School, Boston, U.S.A. \\ 3. MD, PhD, Affiliate Professor of the Department of Surgery, Federal University of São Paulo (UNIFESP), São Paulo. Brazil.
}

\begin{abstract}
Microsurgical techniques have been used in many surgical specialties as well as a broad application in surgical research.. It demands high technical skills and continued training. The microsurgical skills should be first mastered in the lab before to be employed in the clinical practice. The microsurgical lab has a dual role: the training of residents and specialized surgeons and the support for the high qualified scientific research in experimental surgery. Here, it is presented (showed) the organization of a microsurgical lab, including area and equipments, furthermore there is a proposal that schoolhospitals that offer microsurgical procedures, should have a microsurgical laboratory.
\end{abstract}

Key words: Microsurgery. Laboratory Equipment. Teaching. Education.

\section{RESUMO}

As técnicas microcirúrgicas têm sido usadas em várias especialidades cirúrgicas, assim como uma ampla aplicação na pesquisa cirúrgica. A realização de microcirurgia exige alta qualidade técnica e treinamento contínuo. O completo domínio das técnicas de microcirurgia deve ser obtido primeiro no laboratório antes de ser empregada na prática clínica. O laboratório de microcirurgia tem uma dupla função: o treinamento de residentes e cirurgiões especialistas e o suporte para a investigação científica em cirurgia experimental. Nesse artigo está apresentado um modelo de laboratório de microcirurgia, incluindo a área e os equipamentos, além da proposta de que os hospitais-escola, que ofereçam procedimentos microcirúrgicos, sejam equipados com laboratório de microcirurgia.

Descritores: Microcirurgia. Equipamento de Laboratório. Ensino. Educação.

\section{Introduction}

Nowadays, the organization of a microsurgery unit in university hospitals, both in experimental and clinical level, is very important ${ }^{1}$. Microsurgical techniques have been increasingly used in many surgical specialties. It has also been intensively used in surgical research as rodents became standard models ${ }^{2}$.

To offer a program of clinical microsurgery it is fundamental that the institution establish a specialized laboratory, where most performed procedures can be intensively trained. The microsurgical skills have to be obtained first in the lab and not directly with patients. In the microsurgical lab one can learn how to operate the surgical microscope, become familiar with the bi-dimensional operative field and the use of micro-instruments, and learn the principles of microsurgical technique ${ }^{2,3}$. The lab also promotes the scientific interest of graduate and postgraduate students, as well as stimulates interdisciplinary cooperation among researches. In Brazil, there is a lack of microsurgeons because there are only few specialized training centers and courses. The great majority of surgical departments do not have adequate microsurgical laboratories which allow learning and continuing training. Most of qualified personal have obtained specialized training abroad. A good experience was developed at microsurgical lab of the Federal University of São Paulo, where some surgeon residents and medical students have been learning about and practising microsurgery since 1998. Recently, it was organized the first basic microsurgical course for transplant surgeons during the IX Brazilian Congress of Transplants, and this experience was so successful that will be repeated during the next congress. Here, we emphasize the importance of the microsurgical laboratory, describe which is the basic equipment needed and describe a model that could be implemented in university hospitals.

\section{Methods}

Organization and logistics of a microsurgical laboratory

The microsurgical lab has to be approved by the ethic commission of the hospital/university and be registered in the animal care state department in order to perform training and experiments with animals. The lab should be coordinated by the surgical department and led by a qualified trained 
microsurgeon professional. However, it should allow open access to other departments that perform microsurgical procedures or research. The coordinator administrates the course program and organizes the time schedule for training of all participants. The possibility of free access to the lab in a 24hours-basis, including the weekends, allows more flexibility to training and optimization of the use of microscopes. So, the advanced trainee, who already masters the basic skills and does not need direct orientation, can continue his training alone in a very flexible way.

\section{Physical structure of the lab}

The proposed microsurgical training center should be located preferentially close to the animal care facility and have both an operation and a conference room. The conference room equipped with a computer and a beamer and a specialised library (with videos, books and articles on microsurgery), is important for literature search, presentations and discussions. The microsurgery room for three microscopes should have at least $20 \mathrm{~m}^{2}$ and be located in a illuminated and quiet area. The working benches should be preferably fixed on the floor to be more stable and avoid vibration, and should allow that two persons (trainee and instructor) seat opposite to each other (Figure 1). The operator chair should be comfortable have wheels, and allow height regulation. A closet for storing surgical intruments and other materials, as well as a sink and tap to wash the instruments are also desired.

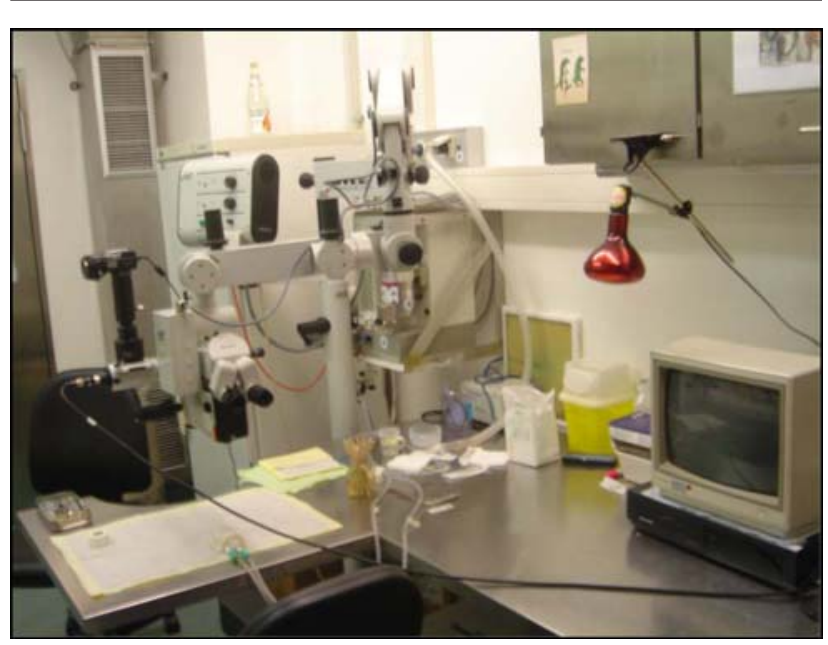

FIGURE 1 - Example of a microsurgery training unit with a surgical microscope connected to a digital camera and video-monitor system

\section{Material and equipments}

Microscope and loupes: The most appropriate surgical microscope for experimental use is the stereomicroscope (tabletop or bench microscope, Figure 2) with integrated halogen illumination and magnification from 2 up to 40 times. The control of light intensity, focus and zoom can be manually operated; once sterilization is not important and automatic (operated through a pedal) microscopes are much more expensive. The microscope should have double optic system or be equipped with a video camera connected to a monitor. This allows the trainee to observe the instructor working or to be oriented and evaluated while he performs a procedure. It is also desired that the microscope can be connected to a digital camera and a video recording system. The possibility to register images is important to illustrate publications and for training.

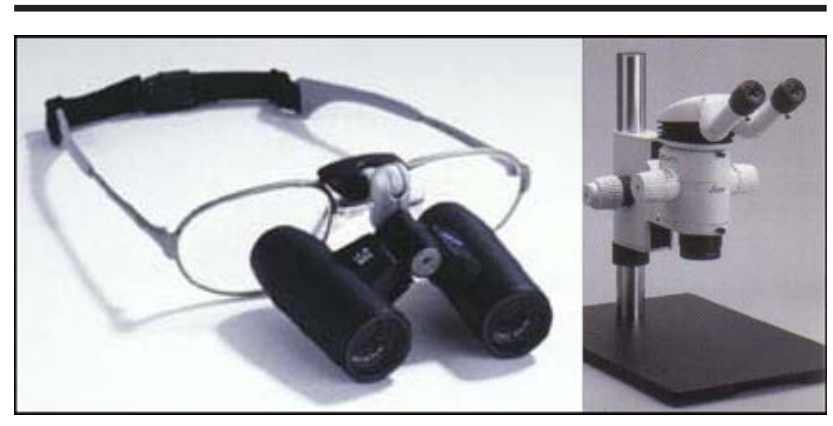

FIGURE 2 - Surgical loupe and a bench microscope

The trainee can record his own microsurgical procedures, and then analyze his performance and discuss it with the instructor. The surgical loupes (prism loupe) are cheaper and mobile compared with a microscope, however it can not be used for all microsurgical procedures. It can generally provide only two to eight times magnification. The greater the magnification, the more difficult is to maintain a sharp image. It can have a fixed or regulated interpupilar distance (Figure 2). The advantage of a loupe with regulated interpupilar distance is that it can be adjusted and used for more than one person. Some loupes can be worn over the normal glasses, or they are built integrated into glasses with the desired dioptry. The working distance (distance between the eyes and the operative field) is preset and can not be regulated. So, it is important before buying a loupe to know the working distance, which depends on the height of the operator and if he will use it while standing or sitting.

\section{Microsurgical instruments}

Ideally, every trainee should have his own set of instruments and surgical loupe since the technical quality of anastomosis is very dependent on the quality of instruments and the familiarity with them. However, the price of instruments is very high, so that the institution should offer at least 3 sets of basic instruments for common use. There are many instrument companies and the quality and price vary enormously. Titan instruments are more resistant against corrosion, lighter and not-magnetized (which facilitates needle handling). However, they are more expensive. The basic microsurgical instrument set consists of; a micro-needle holder, dissection micro-scissors (spring scissors), and two fine forceps - a straight with $0.1 \mathrm{~mm}$ tip and a curved one with $0.3 \mathrm{~mm}$ tip. The advanced instrumental set varies according the surgical specialty. In general, besides the basic instruments, it should have: vascular micro-clamps (micro-serrefines, bulldogs), clamp applicator, vascular dilators, hemostatic forceps, retractors, plastic stents, and catheters. 


\section{Needle and sutures}

The threads used for microsurgery are monofilamentar and nonabsorbable. For suturing veins, arteries, lymphatics and nerves it is recommended to use cylindrical (atraumatic) needles, while for other structures, like the deferent duct and fallopian tubes, sharp needles are preferred. The diameter of the threads is fundamental for the quality of the anastomosis. For vessels between 0.5 and $1.0 \mathrm{~mm}$ of diameter it is recommended to use 11-0 thread (needle of $75 \mu \mathrm{m}$ and thread of $18 \mathrm{~mm}$ ), for vessel between 1.0 and $3.0 \mathrm{~mm}$ the $10-0$ thread (needle of $100 \mu \mathrm{m}$ and thread of $22 \mu \mathrm{m}$ ), while for larger vessels the sutures 7-0 and 8- $0^{3}$. Microsurgical sutures are very expensive and for training purposes it is recommended that suture rests used in the clinic be reused in the lab, as sterilization of instruments and sutures does not influence the quality of procedures and results of most experimental studies. There is also the possibility of using lab package sutures (non-sterilized), which are much cheaper, although not commercialized in Brazil.

\section{Bipolar coagulation forceps}

This equipment is dispensable, once hemostasia should be performed preferentially by ligatures, as the bipolar cauter can promote vascular spasm. If the bipolar is used it should be applied saline solution in the field, otherwise it can stick to the structures and cause vascular tears when removed. The Doppler and electromagnetic flow meter can be used to test the permeability of the vessel and to measure the blood flow after the anastomosis, being important to compare results and perform studies on vascular spasm. Suction machine is generally not necessary. A gas vaporizer for halothane, although important and safe for the personal (as the anesthesia gas circulates in a closed circuit) and it facilitates the control of anesthesia, is very expensive. Other basic equipments such as: anesthesia induction chamber; refrigerator (to store samples and drugs), animal clippers, heating pad and heating lamp for warming the animal during and after the procedure are also desired. An ultrasonic washing system facilitates the cleansing of microinstruments and prolongs their working life.

\section{Conclusion}

There is no doubt that establishing microsurgical labs in university hospitals contributes to increase the technical quality of procedures and the number of microsurgeons as well as higher qualified scientific research in experimental surgery.

\section{References}

1. Martins PNA. A importância da microcirurgia experimental para transplante de órgãos. Acta Cir Bras. 2003; 18:59-61.

2. Thiede A, Timmermann W., Gassel HJ. Experimental microsurgery as an educational concept and scientific basis for research group: principles of technical development of animal models in transplantation research. In: Timmermann W, Gassel HJ, Thiede A, Zhong R. Organ transplantation in rats and mice. 1ed. Springer; 1998. p.17-24.

3. Green CJ. Organisation of a microsurgical laboratory. $\mathrm{Br}$ J Plast Surg. 1990;43:641-4.

4. McC O’Brien B, Morrison WA. Micro-instrumentation and microsurgery. In: Reconstrutive microsurgery. 2ed. Edinburgh: Churchill Livingstone; 1987. p.12-9.

\section{Acknowledgements}

Coordenação de Aperfeiçoamento de Pessoal de Nível Superior (CAPES/DAAD) - Doctoral grant from National Council for Scientific and Technological Development (CNPq), Research Productivity Scholarship.

\section{Correspondence:}

Paulo Ney Aguiar Martins

221 Longwood Ave, Rm 309

Harvard Medical School

Boston, Ma. 02115

U.S.A.
Conflict of interest: none Financial source: CAPES/DAAD

Received: December 08, 2005

Review: January 10, 2006

Accepted: February 12, 2006

\section{How to cite this article:}

Martins PNA, Montero EFS. Organization of a microsurgery laboratory. Acta Cir Bras. [serial on the Internet] 2006 MayJune 21(3). Available from URL: http://www.scielo.br/acb. 